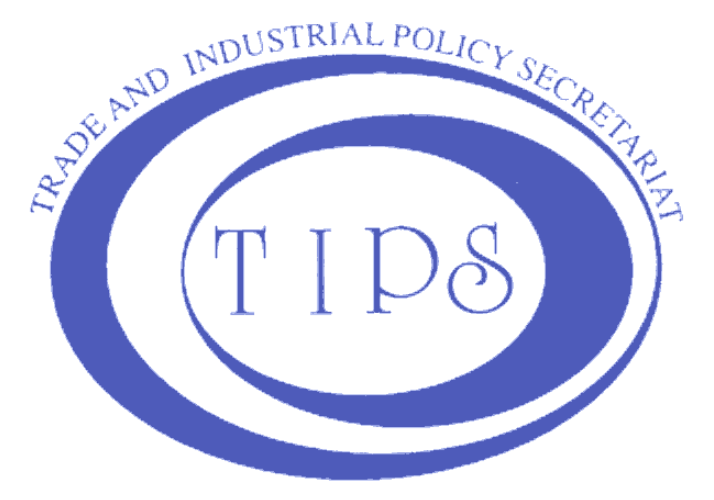

2000 Annual Forum

at Glenburn Lodge, Muldersdrift

\title{
THE MACRO IMPLICATIONS OF HIV/AIDS IN SOUTH AFRICA: A PRELIMINARY ASSESSMENT
}

\author{
Channing Arndt \\ Department of Agricultural Economics \\ Purdue University
}

Jeffrey D. Lewis

The World Bank 


\title{
THE MACRO IMPLICATIONS OF HIV/AIDS IN SOUTH AFRICA: A PRELIMINARY ASSESSMENT
}

\author{
Channing Arndt \\ Department of Agricultural Economics \\ Purdue University \\ Jeffrey D. Lewis \\ The World Bank
}

Revised

August 2000

Special submission to the South African Journal of Economics.

The views expressed in this paper are those of the authors, and should not be attributed to the organizations with which they are affiliated. 


\begin{abstract}
In this paper, we report on the preliminary results from an analysis of the macro impact of HIV/AIDS in South Africa. We have constructed an economywide simulation model that embodies the important structural features of the South African economy, into which we have added major impact channels of the HIV/AIDS epidemic. Using available demographic estimates for the impact of the epidemic (on labor supply, death rates, and HIV prevalence) along with assumptions about behavioral and policy responses (household and government spending on health, slower productivity growth), we use the model to generate and compare two scenarios: a hypothetical "noAIDS" scenario in which the economy continues to perform as it has over the last several years, and an "AIDS" scenario in which the key AIDS-related factors affect economic performance.

Focusing on the differential between the "no-AIDS" and "AIDS" scenarios, we find that the impact of the epidemic could be substantial. Over the 1997-2010 simulation period, GDP growth rates in the two scenarios diverge steadily, reaching a maximum differential of 2.6 percentage points. The result is a GDP level in 2010 that is 17 percent lower in the "AIDS" scenario; an alternative measure of "non-health, non-food absorption" is 22 percent lower by 2010. While some of this decline is due to the lower population associated with the "AIDS" scenario, per capita GDP does drop by around 8 percent. In fact, our simulations suggest that, despite the fact that AIDS impacts the high-unemployment unskilled labor category more than others, the net effect of higher AIDS-related mortality and slower growth is to leave the unemployment rate largely unchanged.
\end{abstract}

We also use the model to "decompose" the overall decline in growth performance into the contribution of the various channels. Given our current assumptions, the largest share (close to half) of the deterioration in growth is attributable to the shift in government current spending towards health expenses (which increases the budget deficit and reduces total investment), while an additional third stems from slower growth in total factor productivity (TFP). The decomposition illustrates the importance of considering the slow moving nature and hence long duration of the epidemic. If the epidemic imposes a drag on the rate of accumulation of knowledge (reduced TFP growth) or the rate of accumulation of capital (through a switch from savings to current expenditure), these effects become amplified over time. Over the course of a decade, the implications for macroeconomic performance are substantial.

Looking forward, our analysis suggests several avenues for further investigation. First, the parameters used in specifying the various AIDS effects are based on fairly limited empirical evidence, and it will be important where feasible to supplement these with additional data. For example, we have limited the impact of AIDS on household expenditure patterns to an assumed increase in health service spending, but there may well be other shifts that will occur and that could be incorporated, based on survey results. Second, there are important dynamic effects that are not yet included in the model: for example, lower private and government spending on education (because of higher AIDS spending) will slow down skills accumulation and change labor force growth rates. Third, consideration must be given to how to capture the impact of alternative "intervention" policies - for example, at present there is no feedback between possible government policies to slow the spread of AIDS, and the demographic (and subsequent economic) trajectory of the epidemic. 
Finally, interactions between the epidemic and alternative growth and development strategies should be examined. We find that interactions with key economic features, such as the unemployment rate, do not necessarily conform to the results that one might expect from a casual analysis. And, key policy decisions, such as financing for AIDS related government expenditures, are shown to be very important. These results suggest that, while the human crisis appears to be practically unavoidable, appropriate economic policy measures have the potential to significantly palliate the negative economic effects of the epidemic. For the policy-making process, the slow moving nature of the epidemic needs to be borne firmly in mind. The AIDS crisis does not require the snap policy decisions of, for example, the Asia financial crisis. Instead, deliberate speed, careful planning, and competent execution by government and other actors could substantially ameliorate the economic aspects of the AIDS crisis. 


\title{
THE MACRO IMPLICATIONS OF HIV/AIDS IN SOUTH AFRICA:
}

\section{A Preliminary Assessment}

\author{
Channing Arndt and Jeffrey D. Lewis*
}

\section{BACKGROUND}

South Africa now stands at the brink of a full-blown AIDS crisis. Recent demographic work summarized in two reports prepared by ING Barings $(1999,2000)$ estimates that, since the onset of the AIDS epidemic, more than 500,000 South Africans have died of AIDS-related causes. By 2015, this number is projected to grow by a factor of 20, to more than 10 million deaths. By 2008 , overall life expectancy in South Africa is forecast to fall from its pre-epidemic high of 65 years to only 40 years. While modification of high-risk behaviors could reduce AIDS-related death rates, the long delays between infection and death mean that behavior change now would only begin to reduce the number of AIDS deaths in five years time with the full affect lagging by a decade or more. With an HIV infection rate currently estimated at almost 20 percent of the adult population (and projected to increase), prospects for avoiding a major human development crisis over the next decade and beyond are dim.

The key question now is how to deal with the impending crisis. The epidemic has moved beyond its earlier status as a health issue to become a development issue, with social, political, and economic dimensions. This paper focuses on the economic aspects. As we begin to recognize the magnitude of the crisis (as measured by the number of AIDS-related deaths), characteristics of those affected (adults in their prime working years), and the many different channels through which the epidemic impacts the economy (skills availability, savings, demand patterns, productivity, etc.), it is important to try to sort through and evaluate how these myriad factors are likely to affect key economic outcomes: sustainable growth, employment creation, poverty and income distribution. In addition, it is critical to consider public policy choices in the context of the epidemic.

While the research and policy analysis agenda is large, our own objectives in this paper are more modest: we hope to contribute to these efforts by undertaking a preliminary analysis of the macroeconomic effects of the AIDS epidemic for South Africa using an economywide modeling framework. The outline of this paper is as follows: first, we briefly review the major channels through which the HIV/AIDS epidemic affects economic activity. Next, we describe the analytic

\footnotetext{
* This paper was originally prepared for the International AIDS Economics Network (IAEN) Symposium on "The Economics of HIV/AIDS in Developing Countries" held in Durban, South Africa on July 7-8, 2000. The research was supported by the World Bank as part of its continuing efforts to promote analytic work and dialogue on South African development issues. We would like to thank Sherman Robinson for his insights and assistance during preparation of the paper. Also, comments from participants at Bank seminars and at the Symposium, in particular Phil Compernolle and Mead Over, who served as discussants for the paper, are also gratefully acknowledged. The views expressed are our own, and do not necessarily reflect those of the institutions with which we are affiliated.
} 
approach employed in this paper, which involves constructing a disaggregated model of the South African economy that embodies the important AIDS-economy linkages identified above. Finally, we use the model to generate alternative medium-term scenarios to simulate the quantitative impact of these AIDS-related effects on macroeconomic performance.

\section{THE IMPACT OF HIV/AIDS ON ECONOMIC ACTIVITY}

In considering how to analyze the macro impacts of HIV/AIDS, there are several salient features of the AIDS epidemic that are likely to have substantial economic implications:

- AIDS tends to strike young adults. According to the data presented by ING Barings (1999), most AIDS-related deaths are likely to occur in the 25 to 45 year age cohort. As a result, AIDS not only reduces life expectancy and the rate of population growth, it will also increase the burden on the working age population, who will be required to care for the young and the sick. ${ }^{1}$

- AIDS is very slow moving. The demographic projections employed by ING Barings (1999) estimate the median span between infection and death at 8-10 years. ${ }^{2}$ During much of this period, the HIV positive individual may experience relatively few direct symptoms, and employment and productivity may be only marginally affected. But with the gradual onset of AIDS (usually during the last 2 years), HIV positive individuals are likely to have declining labor productivity, and to incur increasing and substantial medical costs over the period.

- Infection rates differ by skill class. Analysis in the ING Barings report (1999) suggests that semi-skilled and unskilled workers exhibit a peak infection rate nearly three times the rate for highly skilled workers (these results are based largely on the different racial and age composition of the skill classes). Given these differentials in skill-based infection rates, and the current factor endowments in the economy (abundance of unskilled labor, scarcity of skilled labor) the AIDS epidemic will impact factor demands (for both labor and capital) and relative factor returns.

These features of the AIDS epidemic will combine and interact with South Africa's economic structure to affect factor returns, employment, income distribution, savings rates and other economic variables. For example, if one views wages for unskilled workers as rigid and set well above market-clearing levels, then the level of employment becomes the adjusting variable in response to shocks. If AIDS reduces labor productivity for unskilled labor, employment would be expected to decline (ceterus paribus). ${ }^{3}$ Negative impacts on employment might offset the decline in

${ }^{1}$ Whether the standard "dependency ratio" measure (under 15 and over 64 relative to working age population) will increase remains ambiguous, as it will depend on relative growth rates of different population groups, which will in turn be affected by rates of transmission to infants and the impact on fertility. High infection rates among infants and/or lower fertility would lead to a much older population than would be expected without the epidemic.

2 This estimate is based on the medical technologies currently available in South Africa. Other estimates are lower. For example, Gregson, Zaba, Garnett, and Anderson (2000) use a median span of 6.5 years between infection and death when projecting the demographic impact of the epidemic in a series of countries in sub-Saharan Africa including South Africa.

${ }^{3}$ Note that if employment is the equilibrating variable, then the adjustment response translates directly into output changes and (hence) affects real GDP. 
unskilled labor supply induced by the epidemic leaving an ambiguous impact on the unemployment rate for unskilled workers. Savings rates are also likely to be affected. Most obviously, AIDS affected households are unlikely to have high savings rates.

As the epidemic spreads through the economy, and more information becomes available, it is easy to identify an ever-expanding list of impacts: on individuals, households, and firms. But for purposes of modeling the economic impact, it is not enough to make long lists: the key challenge is coming up with sensible stories about the "hooks" or channels through which the impact of AIDS will be transmitted through to the rest of the economy.

Box 1 provides a non-exhaustive list of the range of factors and possible channels of impact. Given this list, the main task of our analysis is to articulate and empirically specify these channels: how they operate, how big the individual effects are and over what time horizon, and how they interact. It is important to note that some important channels identified in this list have been omitted from our analysis. In particular, the implications of increased insurance/benefits costs and asset sales are not considered, orphans are only considered to cause a modest increase in social spending, and the implications of lower investment in human capital (e.g., as a result of lower education and health spending) are not endogenously considered. In addition, while our modeling approach is well-suited to examining class bias and income distribution impacts of the epidemic, we do not consider these issues in this preliminary assessment.

\footnotetext{
Box 1: Major Channels of HIV/AIDS Impact on the Economy

For firms:

- insurance/benefits up

- disruption/absenteeism

- worker experience down/morbidity

For government:

- AIDS spending up

- production structure shifts

- household incomes, spending shift

For households:

- loss of income/orphans

- caring for HIV/AIDS

$\Rightarrow$ vulnerable households require transfers $\Rightarrow$ changed expenditure patterns, reduced savings, asset sales, lower investment in human capital

For the macro economy:

- lower physical \& human investment $\Rightarrow$ reduced growth trajectory

- class biased impacts

$\Rightarrow$ affects costs, profits, savings

$\Rightarrow$ affects overall productivity

$\Rightarrow$ affects labor productivity

$\Rightarrow$ affects other spending, deficit

$\Rightarrow$ affects revenue from VAT, trade taxes

$\Rightarrow$ affects income tax receipts, transfers

$\Rightarrow$ uneven welfare effects
} 


\section{ANALYZING The MACro IMPACT OF AIDS: AN ECONOMYWIDE APPROACH}

In our paper, we concentrate on the implications of the epidemic for the medium-term growth prospects of the South African economy. The impact will be felt through a number of different channels: through pressures on public spending, from the effect on productivity/training, from shifts towards current spending away from human and physical capital investment, from firms taking actions to reduce dependence on labor and control AIDS-related costs, etc. We simulate the impacts (and interactions) among these forces using an economywide computable general equilibrium (CGE) model of South Africa.

CGE models have a number of features that make them suitable for examining "crosscutting" issues such as the impact of AIDS.

- They simulate the functioning of a market economy, including markets for labor, capital, and commodities, and provide a useful perspective on how changes in economic conditions will likely be mediated through prices and markets.

- Unlike many other partial equilibrium or aggregate macro approaches, they are based on a consistent and balanced set of economywide accounts (called a Social Accounting Matrix, or SAM), which requires (among other things) that key behavioral and accounting constraints (such as budget constraints and balance of payments equilibrium) are maintained, which in turn serves as an important check on the "reasonability" of the outcomes.

- Because they can be fairly disaggregate, CGE models can provide an economic "simulation laboratory" with which we can examine how different factors and channels of impact will affect the performance and structure of the economy, how they will interact, and which are (quantitatively) the most important.

\section{Features of the Basic CGE Model ${ }^{4}$}

The South African model belongs to a class of models that in recent years have been applied to issues of trade strategy, income distribution, and structural change in developing countries. Economic decision-making is the outcome of decentralized optimizing by producers and consumers. A variety of substitution mechanisms are specified in these models, with substitution among labor types, between capital and labor, between imports and domestic goods, and between exports and domestic sales all occurring in response to variations in relative prices. Institutional rigidities and imperfect markets can be captured by the exogenous imposition of features such as immobile sectoral capital stocks, labor market segmentation, and a fixed exchange rate, which together limit a neoclassical interpretation of the models but permit their more realistic application to developing countries.

\footnotetext{
${ }^{4}$ Thorough expositions of this class of models are available elsewhere, so the treatment here will be brief, and focus more on the innovative features of the current model. The standard theoretical treatment of the current generation of CGE models can be found in Dervis, de Melo, and Robinson (1982). See Robinson (1989) for a review of CGE model applications to developing countries.
} 
The model version employed here contains fourteen productive sectors, including three service sectors of particular relevance to analysis of HIV/AIDS: medical and health services, social services, and government services. There are five primary factors of production (professional, skilled, and unskilled labor, informal labor, and physical capital), five household categories representing income distribution quintiles, seven different government functional spending categories, and three government investment categories. ${ }^{5}$

Sectoral production occurs according to a translog production function that determines how capital and labor inputs are combined together in generating value added. ${ }^{6}$ The value added aggregate is then combined with intermediate (material) inputs to produce output according to a fixed coefficients technology. Profit-maximization by producers is assumed, implying that each factor is demanded so that marginal revenue product equals marginal cost. However, factors need not receive a uniform wage or "rental" (for capital) across sectors; sectoral factor market distortions are imposed that fix the ratio of the sectoral return to a factor relative to the economywide average return for that factor. The productivity with which factors combine to produce output in each sector can be affected in two ways: first, the overall productivity can be changed (corresponding to a change in total factor productivity, or TFP) to reflect conditions in which the general productivity of existing technologies is enhanced or reduced (i.e., with the same bundle of labor and capital inputs, less output is produced), and second, the contribution of specific factor inputs (such as labor) can be affected, implying that the effectiveness of each input unit is reduced (i.e., even though there are 100 workers, the effective input is equivalent to only 95 workers).

On the demand side, the South Africa model maintains the standard CGE assumption that domestic goods are imperfect substitutes for traded goods (both exports and imports). Sectoral exports are assumed different from output sold domestically, and are combined using a constant elasticity of transformation (CET) function to form domestic output. This treatment captures explicit differences between exports and domestic goods (such as quality), as well as other barriers preventing costless reallocation of output between the export and domestic markets (such as market penetration costs). Hence, the price of the good on domestic markets need not equal the domestic price of exports, which is determined by the world price, the exchange rate, and exogenous export subsidies. Producers maximize revenue from selling to the two markets, so that the ratio of exports to domestic sales is a function of the price ratio.

As with exports, sectoral imports and domestically produced goods are imperfect substitutes in both intermediate and final uses. Demanders of imports minimize the cost of

5 The basic model data is derived from a 1997 Social Accounting Matrix estimated by WEFA, a South African consulting firm. The WEFA SAM is in fact more disaggregated, including 45 productive sectors, and a household structure differentiated by deciles (with the upper decile further broken down into five groups). But for modeling purposes, we have chosen to use a more aggregated version of their original data.

${ }^{6}$ The translog production function is a more flexible specification than the standard (non-nested) CES production relationship often specified in such models, in that it allows for different elasticities of substitution between input pairs (e.g. between capital and skilled labor, and capital and unskilled labor). This is important in the South African context because of the enormous differences in factor utilization (ranging from high unemployment among unskilled labor to full employment of professional labor) and historic trends in factor use. 
acquiring a "composite" good, defined as a CES aggregation of imports and domestic demand. ${ }^{7}$ Substitution elasticities can vary by sector, with lower elasticities reflecting greater differences between the domestic and imported good. Retaining the small country assumption, the supply of imports is assumed infinitely elastic at a price fixed by world market conditions. The domestic price of the imported good is determined by the world price times the exchange rate, plus any tariffs. The assumption of cost minimizing behavior by demanders implies that the sectoral desired ratio of imports to domestic goods is a function of their price ratio.

Five household categories (based on income distribution quintiles) are distinguished in the model, along with government and corporate accounts. Each group receives income from a variety of sources and has explicit behavioral rules governing savings and expenditure behavior. Firms receive the returns to capital, pay corporate taxes, and receive transfers (from government and the rest of the world). The remainder is divided between corporate savings and household dividends.

Factor income for each of the labor types is distributed to the households using fixed shares, as are corporate dividends. Households are taxed at a fixed rate, and may also receive transfers from the government; they save a fixed fraction of their income (which adds to the pool of domestic savings), with the remaining income spent on consumption.

The government receives tax revenue from import tariffs, export taxes, indirect (excise) taxes, the value added tax, income taxes on corporations and households, and the proceeds from net foreign borrowing. The government spends money on transfers to households and firms, seven different categories of goods and services (including separate health and education), and three types of government investment. The remaining surplus or deficit is added to the available supply of savings in the economy.

Sectoral private consumption is determined through the fixed expenditure shares under the assumption that households have a Cobb-Douglas utility function. Government consumption is also allocated using fixed expenditure shares. Final demand for intermediate goods is the sum of the intermediate demands generated in each producing sector. Investment is allocated using dynamic updating rules discussed in more detail below. Final demand for investment goods is obtained using an activity specific capital coefficients matrix.

Several other features affect simulations with the CGE model. The savings-investment "closure" is savings-driven: in other words, the resources available for investment each year are determined by the sum of savings generated by groups within the economy (households, firms, and government) plus any foreign capital inflow. Government current spending as a share of total absorption $(\mathrm{C}+\mathrm{I}+\mathrm{G})$ is controlled exogenously. The rule for allocation of government spending across the seven expenditure categories can accommodate various "crowding out" mechanisms for example, increased spending on health services can come entirely at the expense of other types of spending or through an increase in the government deficit, which crowds out investment. In the base scenario, AIDS-related government expenditure is deficit financed. Net foreign savings are fixed exogenously, and the exchange rate varies to achieve external balance. In common with other

7 This characterization of imperfect substitutability was developed by Armington (1969). It has since become a standard feature in numerous applied models; see, for example, Dervis, de Melo, and Robinson (1982) and Devarajan, Lewis, and Robinson (1990). 
CGE models, the model only determines relative prices and the absolute price level must be set exogenously. In our model, the aggregate producer price index is fixed, defining the numeraire.

\section{ESTIMATING THE IMPACT OF THE HIV/AIDS EPIDEMIC}

Efforts to estimate and understand the potential macro impact of the AIDS epidemic are not new. A decade ago researchers were constructing macroeconometric models for developing countries that endeavored to incorporate key AIDS-macro linkages, and efforts were made to use CGE models to examine the economywide implications. ${ }^{8}$ While the general conclusion from those earlier investigations was that the macro impact (at least as measured by the standard metric of GDP per capita) would be relatively modest, ${ }^{9}$ the magnitude of the current epidemic combined with the growing recognition that HIV/AIDS is not just a "health" but rather a "development" crisis, along with the mounting evidence of economic losses at the micro level, has created interest in reassessing the macro impact. Finally, South Africa has a very distinct economic structure. Lessons from other countries with high HIV prevalence may not apply to South Africa.

\section{Complementary Research On HIV/AIDS in South Africa}

After a relatively slow start, there are increasing signs of interest in and analysis of the potential macro impact of the HIV/AIDS epidemic on the South African economy. In addition to privately funded research for specific private sector groups (such as the insurance or mining industries), analyses of the demographic and labor market impacts are beginning to appear in the public domain, and various consulting and academic groups are initiating efforts to incorporate the issue in their own work (driven in part by growing demand from private and public sector clients). Various government departments are also undertaking or commissioning analyses that will assess the impact of the epidemic on government programs, both through the direct fiscal impact (e.g., how many resources might be spent on AIDS prevention/care) and on program delivery (e.g., how different groups within the civil service are likely to be affected, and how this will impact on program delivery).

ING Barings (1999, 2000) has prepared two separate research reports, which focus on the demographic and economic impacts, respectively. The Bureau for Economic Research (BER) based at the University of Stellenbosch has produced a summary of current research and findings on the epidemic (BER, 2000), and BER researchers are working to incorporate AIDS effects in their macroeconometric forecasting models. In a recent book, Whiteside and Sunter (2000) focus on the implications of the epidemic for South Africa. The LoveLife foundation, with financial support from the Kaiser Family Foundation and analysis prepared by Abt Associates (2000) and Metropolitan Life, has prepared a resource book on the demographic and economic ramifications of the epidemic, which was distributed to readers of one of the major national business newspapers in

${ }^{8}$ See, for example, Cuddington (1993) for a macro model of Tanzania incorporating AIDS effects, and Kambou, Devarajan, and Over (1992) for a CGE model of Cameroon. This analysis included some of the same channels we focus on here, but because less was understood at that time about the magnitude and attributes of the epidemic (e.g. the differential impact on skills), and the channels through which AIDS would affect the economy, these models provided a fairly "stylized" perspective on the macro impact.

${ }^{9}$ For example, the influential World Bank (1997) report on Confronting AIDS contains a sub-section entitled "AIDS Has Little Net Macroeconomic Impact". 
South Africa (circulation around 700,000). Efforts such as these (and many others) are beginning to raise the profile and rigor of the analysis within South Africa, which is a welcome step towards more open public debate over the likely impact of the epidemic and its policy implications.

It is important to emphasize that the approach taken here is not a substitute for other forms of analysis, including the more focused sectoral, fiscal, or demographic studies identified above. In fact, the relevance of our own efforts depends crucially on obtaining inputs from and providing feedback to other analytic efforts. To build sensible macroeconomic scenarios, assumptions must be made and additional data is needed, including (but not limited to) demographic and labor supply projections (by skill category); broad macroeconomic projection parameters including growth in government spending (by category), budget surplus/deficit targets, and balance of payments trends; estimates of AIDS-related productivity losses by sector or labor skill level; expenditure changes in AIDS affected households; and savings rates by income group. A major purpose of this paper is to "lay bare" our quantitative assumptions on the economic effects of the epidemic to scrutiny by the economic/AIDS research community. We fully expect these assumptions to evolve as our understanding of the various impact channels improves.

\section{Creating Alternative Growth Scenarios}

For our analysis, we have adapted the basic single-period "static" model to include the various channels or mechanisms through which HIV/AIDS will affect the South African economy. The model allows pooling the effects, in order to help sort through how they interact, and how big they might be. But because our interest in the HIV/AIDS story is inherently a dynamic one, we also need to make the model capable of moving forward and looking at growth trajectories. So we must "dynamize" the model by building in a set of cumulation and updating rules (e.g. investment adds to capital stock, after depreciation; labor force growth by skill category; productivity growth).

The purpose of the dynamic equations in the model is to "update" various parameters and variables from one year to the next, and for the most part, the relationships are straightforward. ${ }^{10}$ Growth in the total supply of each labor skill category is specified exogenously, and for the informal, unskilled and skilled labor groups (for which inflexible wages leads to unemployment), the growth trajectory of real wages is also provided. Sectoral capital stocks are adjusted each year based on investment, net of depreciation, and investment is assumed to respond to differential sectoral profit rates so as to preserve the rental rate differentials observed in the base year data. Sectoral productivity growth (TFP) is specified exogenously.

Using these simple relationships to update key variables, we can generate a series of growth scenarios, based on different assumptions about demographic, cost, and other parameters. Using actual data, we first run the model forward from 1997 to 2000, providing an opportunity to "calibrate" the model to recent actual performance (i.e., does the model adequately reproduce recent growth?). We then use the model to generate forward projections from 2001-2010, based on the assumptions and updating relationships provided.

${ }^{10}$ Note that the model is not "dynamic" in the full economic sense of the word, since there are no multi-period optimizing equations and hence no attempt to ensure intertemporal optimality. The simulations are best thought of as a sequence of "lurching equilibria," in which within period (static) equilibrium is first attained, then the model "lurches" forward to the next period, and a new (static) equilibrium is found. 
It is important to note that, at present, we are primarily interested in the differential impact of the HIV/AIDS epidemic. By using the model and varying our assumptions about future trends in key variables (such as labor force growth, HIV/AIDS prevalence, government expenditure, etc.), we can use the CGE model as a simulation laboratory with which to conduct controlled experiments to understand how various factors are likely to affect growth and other key macro variables. In particular, we can compare a hypothetical "no-AIDS" scenario to a more likely "AIDS" scenario, and use the model to decompose the factors that contribute to the performance differences between the two trajectories. From this vantage point, what matters most is whether our benchmark "noAIDS scenario" is more or less reasonable, rather than whether it is "accurate" or not. In other words, building more detail or feedback into the base scenario will only matter if we choose to vary these features across experiments: if they are not factors which we believe will depend on AIDSrelated variables, then including them will make little difference to the differential among scenarios on which we are focusing.

\section{Features of the Alternative Scenarios}

Box 2 summarizes the key channels incorporated into our scenario, along with the assumptions made in each case. As noted above, we have not attempted to incorporate all the effects identified in Box 1. For those effects incorporated, we use the model to try to sort out how big each is likely to be, after choosing parameters based on available research (in some cases) or simple conjecture. An appendix provides details on demographic assumptions.

\section{Box 2: Features of the AIDS Scenario}

\begin{tabular}{|l|l|}
\hline \multicolumn{1}{|c|}{ Effect } & \multicolumn{1}{c|}{ Model Assumption } \\
\hline $\begin{array}{l}\text { Population/labor supply: AIDS epidemic will slow } \\
\text { population growth and have differential impact on } \\
\text { growth in labor supply by skill category }\end{array}$ & $\begin{array}{l}\text { Slower growth in population and in labor force } \\
\text { by skill categories (taken from ING Barings, } \\
\text { 2000; see appendix) }\end{array}$ \\
\hline $\begin{array}{l}\text { Labor productivity: Incidence of HIV/AIDS } \\
\text { among workers will reduce labor productivity, } \\
\text { especially with onset of AIDS }\end{array}$ & $\begin{array}{l}\text { Effective labor input for each skill type reduced } \\
\text { proportionally with projected AIDS deaths (from } \\
\text { ING Barings, 2000) one period hence }\end{array}$ \\
\hline $\begin{array}{l}\text { Total factor productivity: Prevalence of HIV/AIDS } \\
\text { lowers overall productivity (due to hiring and } \\
\text { training adjustment costs, absenteeism, slower } \\
\text { technological adaptation, etc.) }\end{array}$ & $\begin{array}{l}\text { Sectoral TFP growth declines with the onset of } \\
\text { the epidemic falling to one half the "no AIDS" } \\
\text { rate at the height of the epidemic }\end{array}$ \\
\hline $\begin{array}{l}\text { Household spending patterns: HIV/AIDS affected } \\
\text { households will shift spending towards health and } \\
\text { related expenditures }\end{array}$ & $\begin{array}{l}\text { AIDS affected households save nothing and } \\
\text { increase their share of health services spending to } \\
\text { 10-15\% of total spending (depending on quintile), } \\
\text { at the expense of other (non-food) expenditures }\end{array}$ \\
\hline $\begin{array}{l}\text { Government spending: Spread of AIDS will induce } \\
\text { higher government spending on health and social } \\
\text { services, either displacing other spending or } \\
\text { increasing the deficit }\end{array}$ & $\begin{array}{l}\text { Health share of total government recurrent } \\
\text { spending rises from 15\% in 1997 to 26\% in 2010; } \\
\text { non-AIDS related spending remains a constant } \\
\text { share of total absorption. }\end{array}$ \\
\hline
\end{tabular}

Some more details on the AIDS scenario assumptions are worthwhile. With respect to labor productivity, we assume a slightly higher morbidity effect on labor productivity than assumed in ING Barings (2000). Specifically, due to morbidity and absenteeism, we assume that AIDS-afflicted 
workers are half as productive as remaining workers. AIDS-afflicted workers stay on the job for two years. The labor productivity effect for each skill class in period $t$ is assumed to be exactly proportional to the AIDS death rate for that skill class in period $t+1$.

Reductions in TFP growth rates are keyed off of the unskilled labor AIDS death rate. When that rate reaches its maximum value (3.4 deaths per hundred workers in 2010), TFP growth rates in all sectors are halved relative to the "no-AIDS" scenario. The AIDS TFP penalty in earlier years depends upon the ratio of that years AIDS death rate to the maximum value. So, for example, in 2003, the AIDS death rate for unskilled workers is 1.7 per 100 workers. The TFP growth rate in 2003 is two-thirds the no-AIDS growth rate $[1.0 /(1+1.7 / 3.4)=0.67]$.

This overall TFP effect is absent in many earlier analyses. However, the current scale of the epidemic forces one to rethink the assumption of zero impact on TFP growth (or the rate of process improvement). There are at least four reasons to believe that TFP growth rates will be negatively affected. First, while impossible to count precisely, the resources currently directed towards various aspects of the epidemic by government, universities, and firms are clearly large. Furthermore, much of this attention is high level. For example, Clem Sunter, coauthor of Implications of AIDS for South Africa, was until recently the chairman of the Gold and Uranium Division at Anglo American Corporation. This effort comes at an opportunity cost. Second, AIDS will undoubtedly generate a high level of work force disruption. Workers are more likely to be absent and turnover rates are likely to increase. Since South Africa's economy is much more capital intensive than other economies in sub-Saharan Africa, the possibility for idling capital is much greater. Higher training needs are also concomitant to a higher capital intensity. Third, transactions costs in enforcing contracts are likely to increase. Finally, the receptivity of a workforce, where 3 percent of members die each year, an additional 3 percent develop AIDS, and an additional 20 percent or more have their life horizons severely curtailed due to HIV positive status, to implementing process improvements (even if they are developed) is surely not enhanced and may be severely curtailed. All of these factors point to a reduced rate of productivity increase relative to a no-AIDS scenario. ${ }^{11}$

With respect to government spending, our assumptions on government expenditure amount to a 6.9 percent annual real increase in government expenditure on health from 1997 to 2010. This rate compares with a real rate of annual expenditure increase (actual expenditure deflated by the CPI) on health recorded for consolidated government accounts for the period 1992 to 1997 of 5.7 percent (South African Reserve Bank, 1999). ${ }^{12}$ Real expenditure increases for social programs (on orphans for example) is assumed to be much lower at 2.7 percent per annum.

\footnotetext{
${ }^{11}$ Morris, Burdge, and Cheevers (2000) provide a case study of a sugar mill that illustrates some of these points.

12 Even under a generous health care financing scenario, scarce government health resources will be directed towards treating AIDS and related conditions at the expense of other uses. In other sub-Saharan African countries, AIDS expenditure appears to have severely crowded out of other health expenditures, and there is some evidence of a decline in the health status for non-AIDS afflicted populations (World Bank, 1997).
} 


\section{Preliminary Model Results}

Figure 1 provides a reference point for the basic characteristics of the "no-AIDS" scenario as well as some insight into the bottom line results on the economic implications of the AIDS epidemic. The "no-AIDS" scenario postulates relatively low average growth rates during the 19971999 period (around 2.5 percent), consistent with South Africa's performance during this period. Non-AIDS growth rates accelerate slowly and steadily throughout the simulation period, due primarily to capital deepening and projected increases in the rate of accumulation of professional and skilled labor (which are projected based on historical trends).

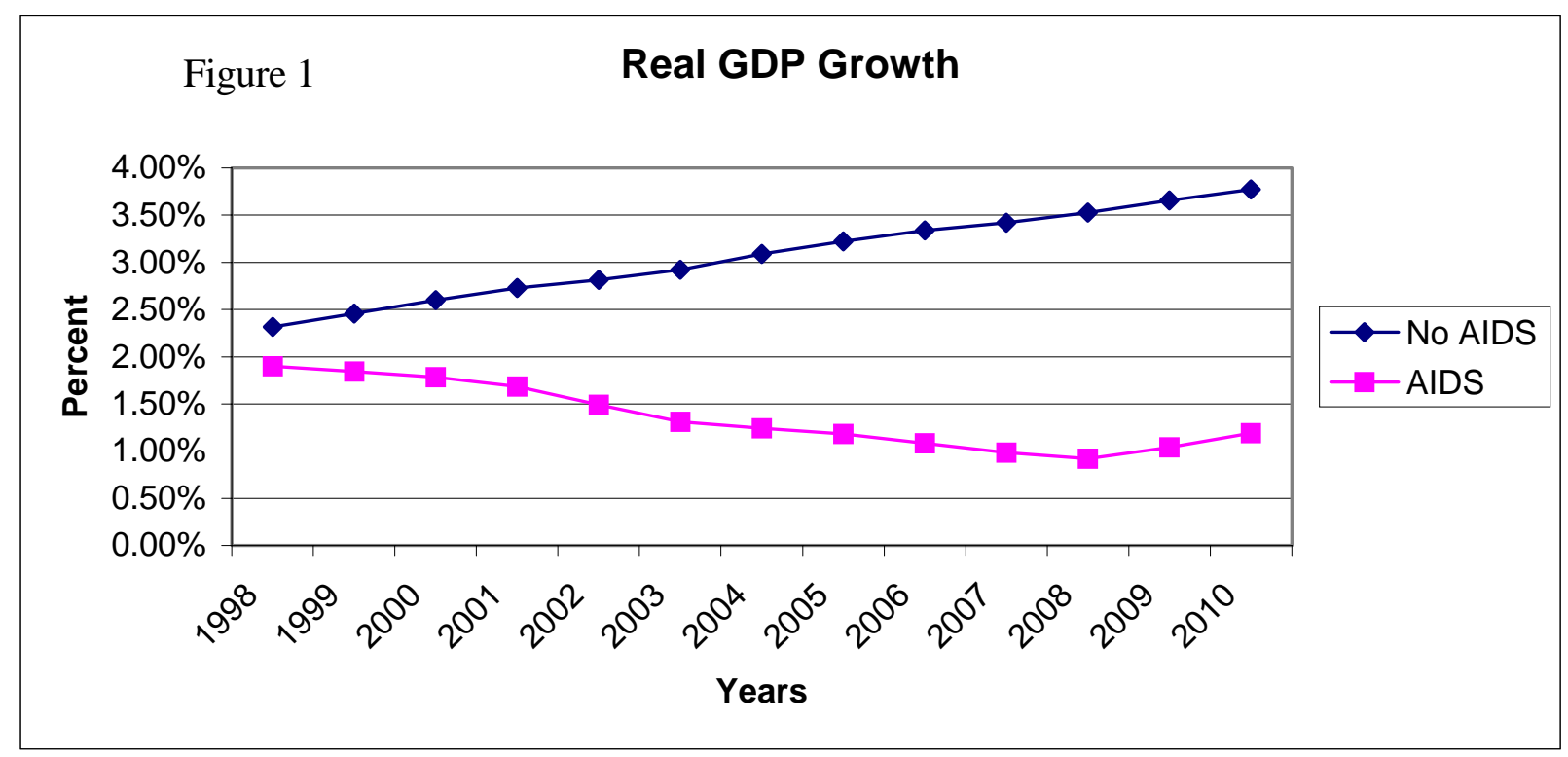

The "AIDS" scenario offers a very different picture. Growth rates in the late 1990s start off at roughly the same level as the "no-AIDS" scenario, due to the (relatively) low incidence of AIDS. However, the growth paths diverge significantly over the simulation period, as the impact of the epidemic becomes more pronounced and affects economic performance through the various channels discussed above. GDP growth rates decline from year to year through 2008 (to only around 1 percent), before rebounding slightly in 2009 and 2010. Differences in real GDP growth rates between the scenarios reach a maximum of 2.6 percent in 2008 .

These differences in growth rates cumulate over time to bring about a substantial divergence in the overall size of the economy. Figure 2 shows that, by 2010, real GDP is about 17 percent below the level attained in the "no-AIDS" scenario. In comparing medium-term performance, such real GDP measures are frequently used as an indicator of aggregate economic welfare. With respect to the AIDS epidemic, there is the broad issue, which we do not address, of whether any GDP or absorption-based indicator can provide an adequate measure of "welfare" in the context of an epidemic that (among other effects) lowers average life expectancy by around 20 years. We do attempt to address a blatant omission in a traditional indicator. In particular, GDP in the "AIDS" scenario contains substantially increased spending on health (both public and private) in order to combat AIDS, which may not represent an "improvement" in welfare relative to the "no-AIDS" 
base. An alternative indicator of welfare might focus exclusively on absorption $(\mathrm{C}+\mathrm{I}+\mathrm{G})$ excluding AIDS-related government expenditures and private expenditures on food and medical services. This measure is defined as "Absorption2" in Figure 2. Real spending on this aggregate (deflated by the consumer price index) is 22 percent lower in the "AIDS" scenario in 2010.

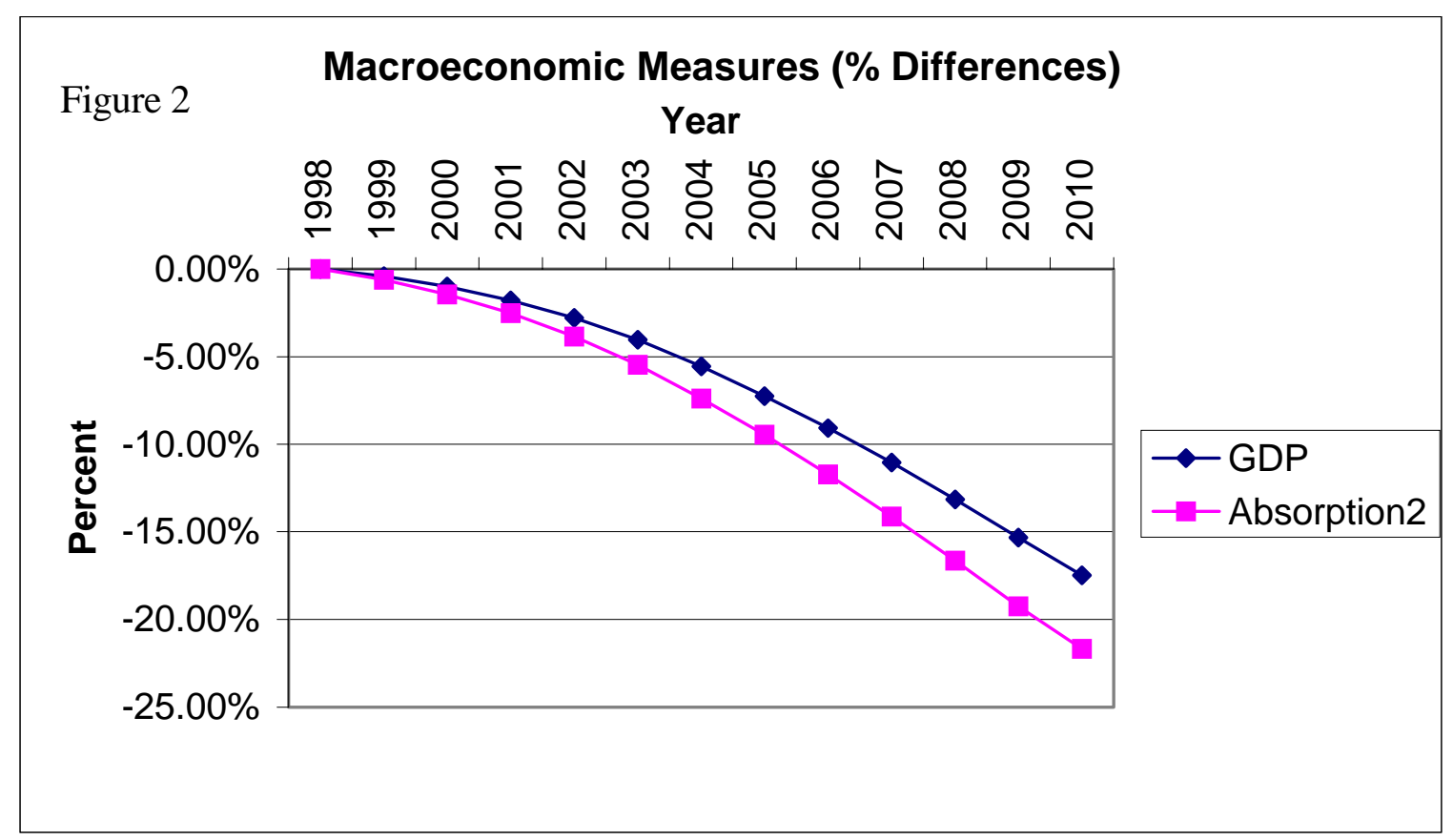

One expects the AIDS epidemic to reduce the overall size of the economy. With fewer factors of production, reduced investment, and lower productivity in the AIDS scenario, the size of the economy is bound to be smaller. But while the size of the economy is smaller, the population is lower as well. Per capita GDP might actually rise. For example, it is widely believed that per capita GDP increased substantially for survivors of the bubonic plague in medieval Europe. Early analyses of the economic impact of AIDS in Africa, such as Kambou, Devarajan, and Over (1992), found per capita income largely unchanged in AIDS versus no-AIDS scenarios. More recently, the result of a negligible impact on per capita GDP has been found for Botswana (BIDPA, 2000).

In contrast, for South Africa, we find a substantial reduction in GDP and Absorption2 per capita. The exact declines are shown in Figure 3. By 2010, per capita GDP is 8 percent lower in the "AIDS" scenario compared with the "no-AIDS" scenario. Moreover, this per capita GDP decline disproportionately lowers non-health and non-food expenditure: Absorption2 per capita declines by 13 percent. So, the survivors of the AIDS epidemic are left with a smaller economic "pie", and more of this pie is directed towards health and food expenditure, so that discretionary expenditures decline dramatically. 
Figure 3

\section{Per Capita Differences}

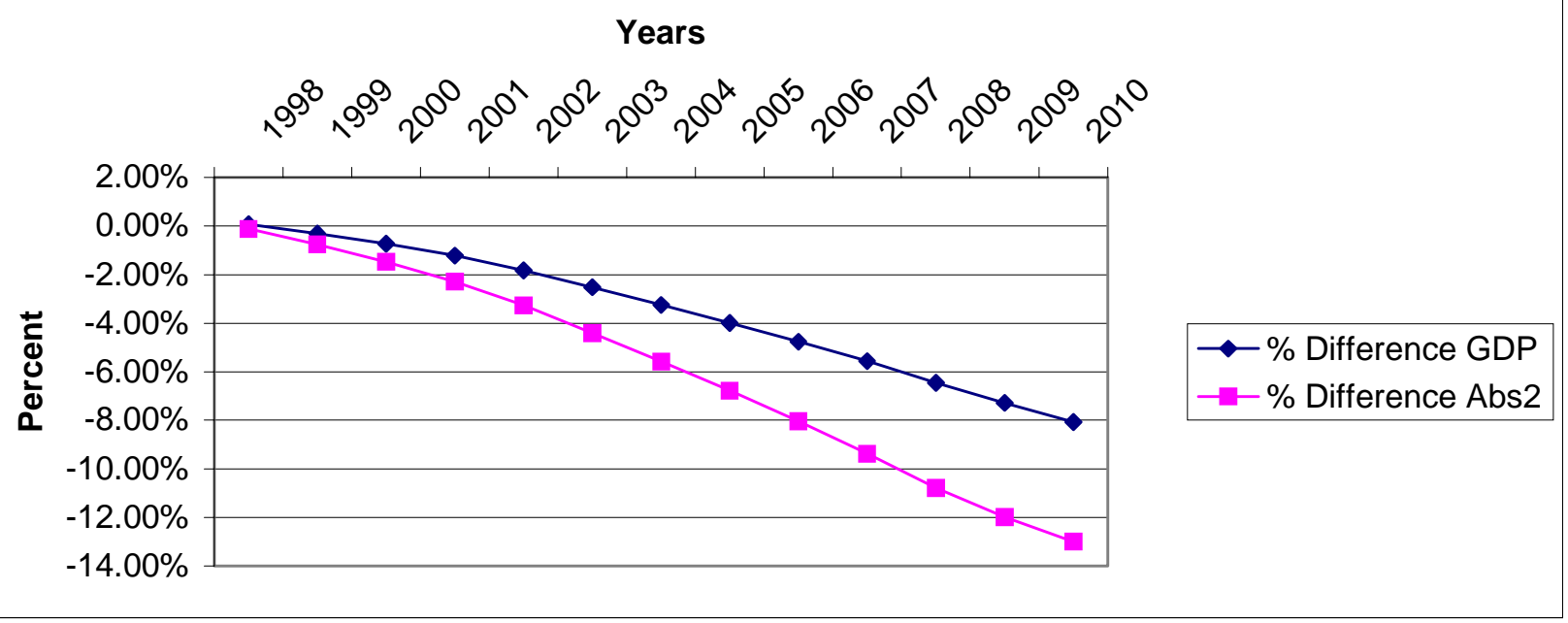

As discussed earlier, one of the advantages of the CGE approach employed here is the ability to capture interactions between the effects of the AIDS epidemic and the existing economic structure as well as the policy environment. One salient feature of the current South African economic structure is a very high rate of unemployment amongst unskilled workers. Since this category of labor exhibits the highest HIV infection rate and the highest AIDS-related death rate, a casual analysis might predict a decline in the unemployment rate since the stock of unskilled labor is set to grow at a much slower rate than in the absence of the epidemic. However, model results contradict this casual analysis. Figure 4 shows that the unemployment rate for unskilled labor actually increases (although only marginally) as a result of the epidemic. ${ }^{13}$ While the unskilled labor pool is smaller, slower growth means that the demand for labor is correspondingly lower. These two effects offset one another leaving the unemployment rate essentially unchanged.

${ }^{13}$ The figure also illustrates the daunting employment challenge facing South Africa. Even with the improved growth rates, relative to the 1990s, in the "no-AIDS" scenario, the unemployment rate continues to rise. One crucial assumption underpinning this growth in unemployment is a 2 percent annual growth rate in the real wage for unskilled labor. Lowering this wage growth incrementally would lead to faster employment growth, and (at some point) unemployment would decline. However, since the 2 percent real wage growth rate assumed here is only slightly over half the average level of real wage growth experienced over the 1970-1999 period, our assumption does not appear unreasonable. 


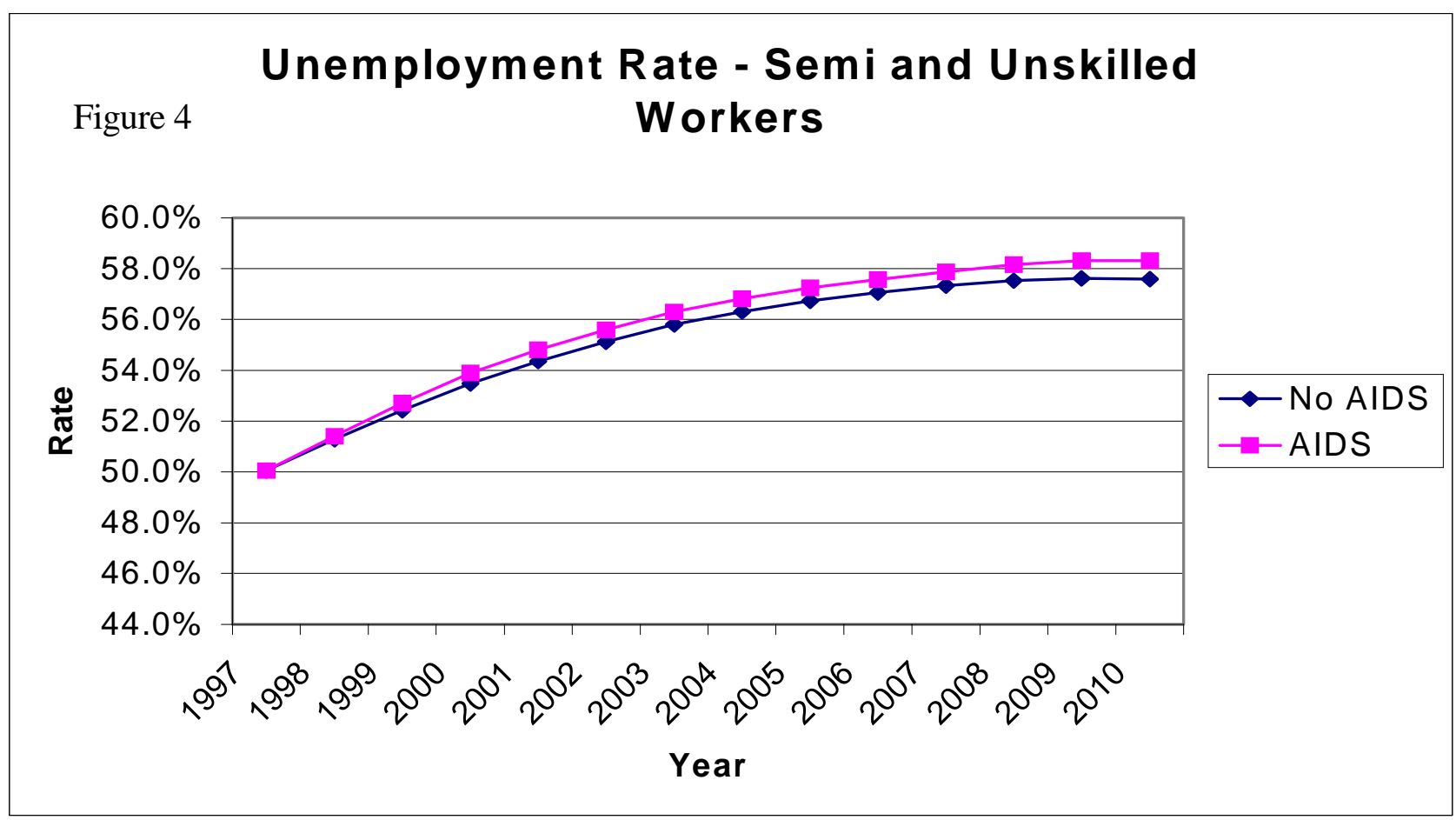

The model also permits us to decompose the total difference between scenarios into the contribution of each component. This gives insight into the relative importance of various effects on an aggregate, such as GDP. Figure 5 portrays the difference in real GDP between the "no-AIDS" and the "AIDS" scenarios decomposed, into four effects. Figure 6 shows the percent contribution of these four elements to the difference in GDP between scenarios in 2010. This decomposition of the magnitude of the various effects contributing to this GDP decline was obtained by progressively eliminating effects from the "AIDS" scenario. ${ }^{14}$ First, the negative impact on overall TFP growth was eliminated. This effect accounted for 67 billion Rand (1997 real) or 34 percent of the difference in real GDP between the "no-AIDS" and "AIDS" scenarios in 2010.

\footnotetext{
14 The reader should be aware that the elimination of various effects is not path independent. As a result, the magnitude attributed to each effect could depend upon the order in which it is eliminated.
} 


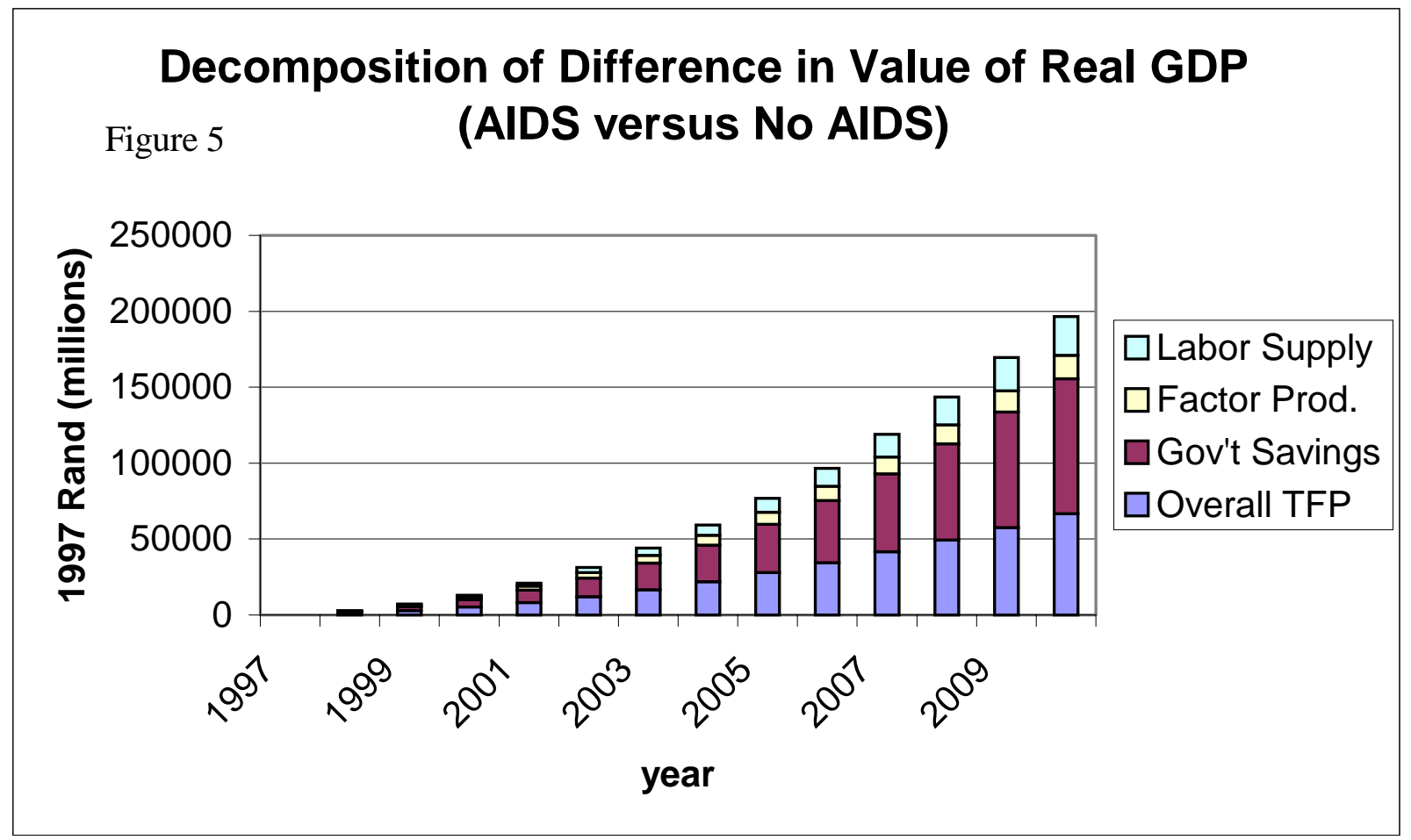

\section{Decomposition of Difference in Real GDP in 2010}

Figure 6 (AIDS versus No AIDS)

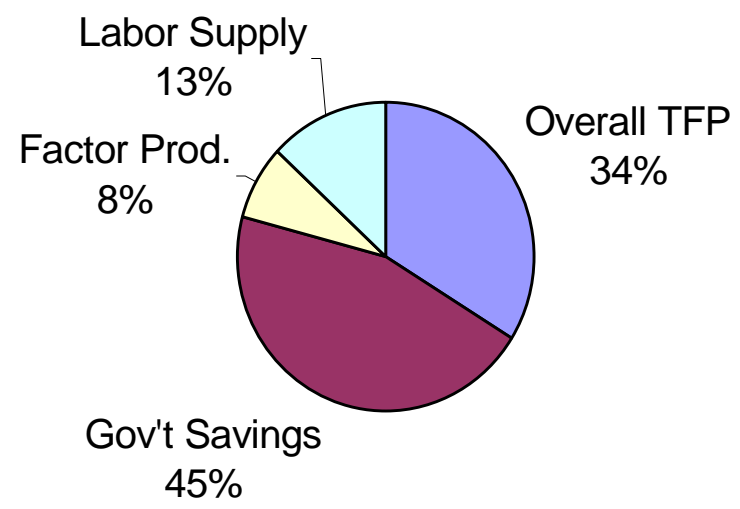


Next, we changed the assumption of government deficit financing of AIDS-related expenditures. In the AIDS scenario, government AIDS related spending from the savings pool causes total savings to decline from 17.0 percent of GDP in 1997 to 14.2 percent in $2010 .{ }^{15}$ Since investment is determined by available savings in the model, this deficit spending "crowds out" private investment, which reduces capital formation and the rate of growth. Instead, AIDS-related government expenditures are assumed to "crowd out" other government expenditures. By assumption, total government recurrent spending remains a constant share of nominal absorption. This change in financing and government expenditure patterns indicates that government deficit spending to finance AIDS-related expenditures accounts for about 45 percent of the real GDP differential. Combined, these first two effects account for about 79 percent of the total GDP decline in 2010. The remaining GDP effect is divided between factor specific productivity declines and reductions in the labor supply. ${ }^{16}$

As mentioned above, the potential economic impacts derived in this study are larger than impacts found in other studies. Compared with earlier studies, two factors drive the differences. First, the magnitude of the epidemic is substantially larger than earlier demographic estimates suggested. Second, early CGE analyses, such as Kambou, Devarajan, and Over (1992), did not contain a time dimension. As a result, the cumulative effects of depressed rates of investment and rates of TFP growth were not able to manifest themselves. These two factors do not apply to the recent study on the macroeconomic impacts for Botswana undertaken by BIDPA, which, consistent with earlier studies, found negligible impacts on per capita income. In this case, the difference in results stems from differences in assumptions about foreign capital inflows. With a diamond dominated economy and an excellent international credit rating, BIDPA assumed that foreign capital inflows would replace any declines in the available domestic savings pool in Botswana. In contrast, for South Africa, we assume that net foreign capital inflow remains constant (in foreign currency) at the low level observed in 1997.

\section{SUMMARY AND CONCLUSIONS}

In this paper, we report on the preliminary results from an analysis of the macro impact of HIV/AIDS in South Africa. We have constructed an economywide simulation model that embodies the important structural features of the South African economy, into which we have added major impact channels of the HIV/AIDS epidemic. Using available demographic estimates for the impact of the epidemic (on labor supply, death rates, and HIV prevalence) along with assumptions about behavioral and policy responses (household and government spending on health, slower productivity growth), we use the model to generate and compare two scenarios: a hypothetical "noAIDS" scenario in which the economy continues to perform as it has over the last several years, and an "AIDS" scenario in which the key AIDS-related factors affect economic performance.

\footnotetext{
${ }^{15}$ Reductions in household savings also contribute to the decline in aggregate savings as a share of GDP; however, households savings rates are already low and only AIDS afflicted households are assumed to reduce savings rates. As a result, the impact of reduced household savings rates on total savings is small.

${ }^{16}$ Any GDP effect related to expenditure switching to health care also is subsumed in the GDP effect attributed to reductions in the labor supply.
} 
Focusing on the differential between the "no-AIDS" and "AIDS" scenarios, we find that the impact of the epidemic could be substantial. Over the 1997-2010 simulation period, GDP growth rates in the two scenarios diverge steadily, reaching a maximum differential of 2.6 percentage points. The result is a GDP level in 2010 that is 17 percent lower in the "AIDS" scenario; an alternative measure of "non-health, non-food absorption" is 22 percent lower by 2010. While some of this decline is due to the lower population associated with the "AIDS" scenario, per capita GDP does drop by around 8 percent. In fact, our simulations suggest that, despite the fact that AIDS impacts the high-unemployment unskilled labor category more than others, the net effect of higher AIDS-related mortality and slower growth is to leave the unemployment rate largely unchanged.

We also use the model to "decompose" the overall decline in growth performance into the contribution of the various channels. Given our current assumptions, the largest share (nearly half) of the deterioration in growth is attributable to the shift in government current spending towards health expenses (which increases the budget deficit and reduces total investment), while an additional third stems from slower growth in total factor productivity (TFP). The decomposition illustrates the importance of considering the slow moving nature and hence long duration of the epidemic. If the epidemic imposes a drag on the rate of accumulation of knowledge (reduced TFP growth) or the rate of accumulation of capital (through a switch from savings to current expenditure), these effects become amplified over time. Over the course of a decade, the implications for macroeconomic performance are substantial.

Looking forward, our analysis suggests several avenues for further investigation. First, the parameters used in specifying the various AIDS effects are based on fairly limited empirical evidence, and it will be important where feasible to supplement these with additional data. For example, we have limited the impact of AIDS on household expenditure patterns to an assumed increase in health service spending, but there may well be other shifts that will occur and that could be incorporated, based on survey results. Second, there are important dynamic effects that are not yet included in the model: for example, lower private and government spending on education (because of higher AIDS spending) will slow down skills accumulation and change labor force growth rates. Third, consideration must be given to how to capture the impact of alternative "intervention" policies -for example, at present there is no feedback between possible government policies to slow the spread of AIDS, and the demographic (and subsequent economic) trajectory of the epidemic.

Finally, interactions between the epidemic and alternative growth and development strategies should be examined. We find that interactions with key economic features, such as the unemployment rate, do not necessarily conform to the results that one might expect from a casual analysis. And, key policy decisions, such as financing for AIDS related government expenditures, are shown to be very important. These results suggest that, while the human crisis appears to be practically unavoidable, appropriate economic policy measures have the potential to significantly palliate the negative economic effects of the epidemic. For the policy-making process, the slow moving nature of the epidemic needs to be borne firmly in mind. The AIDS crisis does not require the snap policy decisions of, for example, the Asia financial crisis. Instead, deliberate speed, careful planning, and competent execution by government and other actors could substantially ameliorate the economic aspects of the AIDS crisis. 


\section{REFERENCES}

Abt Associates (2000). "The Impending Catastrophe: A Resource Book on the Emerging HIV/AIDS Epidemic in South Africa." Published by LoveLife, Parklands (May).

Armington, Paul (1969). "A Theory of Demand for Products Distinguished by Place of Production." IMF Staff Papers. Vol. 16, no. 1 (July), pp. 159-178.

Botswana Institute for Development Policy Analysis [BIDPA] (2000). "Impacts of HIV/AIDS on Poverty and Income Inequality in Botswana." Paper presented at International AIDS Economics Network (IAEN) Workshop, Durban, South Africa (June).

Bureau for Economic Research [BER] (2000). "HIV/AIDS and the South African Economy." Economic Research Note No. 8, Stellenbosch (June).

Cuddington, John T. (1993). "Modeling the Macroeconomic Effects of AIDS with an Application to Tanzania." World Bank Economic Review. Vol. 7, no. 2, pp. 173-89.

Dervis, Kemal, Jaime de Melo, and Sherman Robinson (1982). General Equilibrium Models for Development Policy. Cambridge: Cambridge University Press.

Devarajan, Shantayanan, Jeffrey D. Lewis and Sherman Robinson (1990). "Policy Lessons from TradeFocused, Two-Sector Models." Journal of Policy Modeling. Vol. 12, pp. 625-657.

Gregson, Simon, Basia Zaba, Geoffrey P. Garnett and Roy M. Anderson (1998). "Projections of the Magnitude of the HIV/AIDS Epidemic in Southern Africa." In Implications of AIDS for Demography and Policy in Southern Africa. Alan Whiteside ed. Pietermaritzburg: University of Natal Press.

ING Barings (1999). "The Demographic Impact of AIDS on the South African Economy." Johannesburg (December).

ING Barings (2000). "Economic Impact of AIDS in South Africa: A Dark Cloud on the Horizon." Johannesburg (May).

Kambou, Gerard, Shantayanan Devarajan, and Mead Over (1992). "The Economic Impact of AIDS in an African Country: Simulations with a General Equilibrium Model of Cameroon." Journal of African Economies. Vol. 1, no. 1, pp. 103-30.

Morris, Chester N., David R. Burdge, and Edward J. Cheevers (2000). Paper presented at International AIDS Economics Network (IAEN) Workshop, Durban, South Africa (June).

Robinson, Sherman (1989). "Multisectoral Models." In H.B. Chenery and T.N. Srinivasan, eds. Handbook of Development Economics. Amsterdam: North-Holland.

South African Reserve Bank (1999). Quarterly Bulletin. No. 214 (December).

World Bank (1997). Confronting AIDS: Public Priorities in a Global Epidemic. New York: Oxford University Press. 


\section{APPENDIX}

Table A1: AIDS death rate per 100 workers by category.

\begin{tabular}{|llllllll|}
\hline & 1998 & 1999 & 2000 & 2001 & 2002 & 2003 & 2004 \\
\hline Unskilled & 0.3 & 0.5 & 0.8 & 1.0 & 1.3 & 1.7 & 2.1 \\
Skilled & 0.2 & 0.4 & 0.5 & 0.7 & 0.9 & 1.2 & 1.4 \\
Professional & 0.2 & 0.3 & 0.4 & 0.5 & 0.6 & 0.7 & 0.9 \\
\hline \multicolumn{1}{|l}{} & & & & & & & \\
\hline Unskilled & & 2005 & 2006 & 2007 & 2008 & 2009 & 2010 \\
Skilled & & 2.4 & 2.7 & 3.0 & 3.2 & 3.3 & 3.4 \\
Professional & & 1.6 & 1.8 & 1.9 & 2.0 & 2.1 & 2.1 \\
\hline
\end{tabular}

Source: ING Barings (2000) for years 2000-2010. Figures for 1998 and 1999 were obtained by extrapolation.

Table A2: Labor force growth rates.

\begin{tabular}{|c|c|c|c|c|c|c|c|c|}
\hline & & 1998 & 1999 & 2000 & 2001 & 2002 & 2003 & 2004 \\
\hline \multirow[t]{2}{*}{ Unskilled } & $\mathrm{Hu}$ & $2.93 \%$ & $2.82 \%$ & $2.58 \%$ & $2.12 \%$ & $1.74 \%$ & $1.40 \%$ & $0.97 \%$ \\
\hline & no-AID & $\$ 3.05 \%$ & $3.05 \%$ & $3.05 \%$ & $3.05 \%$ & $2.92 \%$ & $2.85 \%$ & $2.67 \%$ \\
\hline \multirow[t]{2}{*}{ Skilled } & AIDS & $1.52 \%$ & $1.44 \%$ & $1.28 \%$ & $0.96 \%$ & $0.88 \%$ & $0.88 \%$ & $1.08 \%$ \\
\hline & no-AII & $51.60 \%$ & $1.60 \%$ & $1.60 \%$ & $1.60 \%$ & $1.69 \%$ & $1.87 \%$ & $2.24 \%$ \\
\hline \multirow[t]{3}{*}{ Professiona } & 1 AID & 3.0 & $2.97 \%$ & $2.84 \%$ & $2.62 \%$ & $2.51 \%$ & $2.50 \%$ & $2.74 \%$ \\
\hline & no-A & 53 & & 3.1 & 3.0 & $3.06 \%$ & $3.16 \%$ & \\
\hline & & & 2005 & 200 & 20 & 20 & 2009 & \\
\hline \multirow[t]{2}{*}{ Unskilled } & AIDS & & $0.66 \%$ & $0.39 \%$ & $0.20 \%$ & $0.08 \%$ & $-0.05 \%$ & $-0.18 \%$ \\
\hline & no-AI & & $2.58 \%$ & $2.48 \%$ & $2.40 \%$ & $2.33 \%$ & $2.21 \%$ & $2.05 \%$ \\
\hline \multirow[t]{2}{*}{ Skilled } & AIDS & & $1.10 \%$ & $1.03 \%$ & $0.84 \%$ & $0.84 \%$ & $0.93 \%$ & $1.02 \%$ \\
\hline & no-AIDs & & $2.40 \%$ & $2.45 \%$ & $2.34 \%$ & $2.38 \%$ & $2.46 \%$ & $2.51 \%$ \\
\hline & & 2.8 & & & $3.07 \%$ & $3.23 \%$ \\
\hline \multicolumn{3}{|c|}{$\begin{array}{r}\text { Professional AIDS } \\
\text { no-AIDS }\end{array}$} & $3.66 \%$ & $3.76 \%$ & $3.71 \%$ & $3.78 \%$ & $3.92 \%$ & $4.02 \%$ \\
\hline
\end{tabular}

Source: ING Barings (2000) for years 2000-2010. Figures for 1998 and 1999 were obtained by extrapolation. 


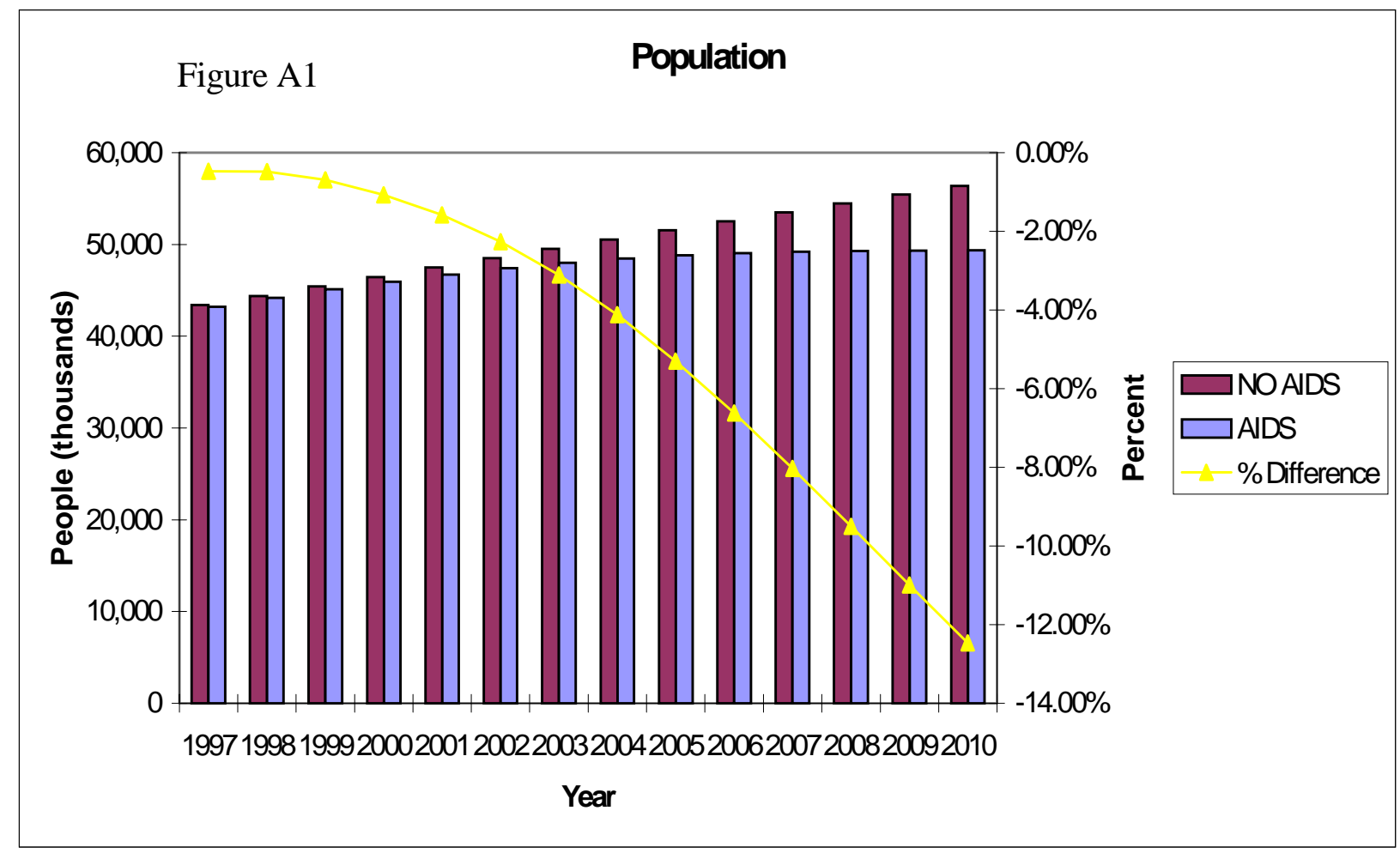

Source: ING Barings (2000). 